American Journal of Pharmacology and Toxicology 4 (2): 17-21, 2009

ISSN 1557-4962

(C) 2008 Science Publications

\title{
Drug Interaction between Salinomycin and Exogenous Adrenaline in Dogs
}

\author{
${ }^{1}$ Hamid Rajaian, ${ }^{2}$ Javad Sajedianfard, ${ }^{3}$ Saeed Nazifi and ${ }^{1}$ Ali Moosavi Kian \\ ${ }^{1}$ Department of Pharmacology, School of Veterinary Medicine, \\ Shiraz University, Shiraz 71345-1731 Iran \\ ${ }^{2}$ Department of Physiology, School of Veterinary, \\ Medicine Shiraz University, Shiraz 71345-1731, Iran \\ ${ }^{3}$ Department of Clinical Pathology, School of Veterinary Medicine, \\ Shiraz University, Shiraz 71345-1731, Iran
}

\begin{abstract}
Problem statement: Salinomycin is a member of ionophore compounds that may be used in ruminants and pigs as growth promoter or to prevent coccidiosis. There are some reports with respect to the in vitro and in vivo sympathomimetic cardiovascular effects of salinomycin. Available reports indicate that adrenergic impact of the ionophore is brought about by an increase in the secretion of endogenous catecholamines. In the present study, the hypothesis that salinomycin probably inhibits the biotransformation of catecholamines was examined. Approach: Ten female dogs weighing 22-29 kg were randomly divided into two equal groups. Two hours before general anesthesia, salinomycin with a dose of $1 \mathrm{mg} \mathrm{kg}^{-1}$ body weight was orally administered to the dogs in group II. Adrenaline $\left(10 \mu \mathrm{g} \mathrm{kg}^{-1}\right)$ was intravenously infused to all animals in both groups 30 min after anesthesia. Urine was collected via urinary catheter during the experiment at different time intervals (0-30, 30-90, 90-150 and 150-210 $\mathrm{min})$. Urine volume at each stage was recorded and urine samples were assayed for vanilmandelic acid (VMA) using spectrophotometric method. Results: Dogs in group I excreted an average of $196 \mu \mathrm{g}$ of VMA in urine compared to $81 \mu \mathrm{g}$ in group II during first half an $\mathrm{h}$, before intravenous infusion of adrenaline. The total amount of VMA excreted in urine during 30-90, 90-150 and 150-210 min after administration of adrenaline to dogs in group I were around 426, 430 and $437 \mu \mathrm{g}$, respectively. The corresponding values in group II were found to be 164,161 and $273 \mu \mathrm{g}$, respectively. In summary, a significant $(\mathrm{p}<0.05)$ decrease in the urinary excretion of VMA was noticed in dogs pretreated with salinomycin. Conclusion/Recommendations: It was generally concluded that the adrenergic effect of salinomycin might be elicited by a decrease in catecholamine catabolism. Measurement of catecholamine concentrations (both parent and metabolites) in serum and determination of other catecholamine metabolites in urine and serum was recommended.
\end{abstract}

Key words: Adrenaline, dogs, drug interaction, salinomycin

\section{INTRODUCTION}

Salinomycin is a monocarboxylic polyether antibiotic with antibacterial and anticoccidial properties $^{[1-4]}$. Ionophores were first described in 1964 by Moore and Pressman ${ }^{[5]}$. They function as mobile cation carriers and have the ability to complex with and transport organic amines ${ }^{[6]}$. Because of its favorable hemodynamic profile, salinomycin has potential as a drug for increasing cardiac output, blood pressure and left ventricular force of contraction and for improving the myocardial blood perfusion and mechanical efficiency of the heart ${ }^{[7]}$. Monensin has also proved to be beneficial in reversing hemorrhagic hypotension produced experimentally in $\operatorname{dog} \mathrm{s}^{[8]}$.

Polyether antibiotics are characterized by multiple tetrahydrofuran and tetrahydropyran rings connected by aliphatic bridges. Other important features, also contributing to their mode of action include a free carboxyl function, many alkyl groups and a variety of functional oxygen groups $^{[9,10]}$. The ionophore antibiotics are fermentation products of various Streptomyces spp. (monensin, salinomycin) and Actinomadura spp. (maduramycin) ${ }^{[11]}$. Salinomycin shows great preferential complexation with monovalent over divalent cations ${ }^{[12]}$. Electrophysiological effects of

Correspondence Author: H. Rajaian, Department of Pharmacology, School of Veterinary Medicine, Shiraz University, Shiraz 71345, Iran Tel: +98 711 6466853/+98 711 2286940/+98 9173072192 Fax: +98 7116466846 
Am. J. Pharm. \& Toxicol., 4 (2): 17-21, 2009

lonomycin A and monensin in cardiac Purkinje fibers have been studied by Tsuchida and Aihara ${ }^{[13]}$ and Tsuchida and Otoma ${ }^{[14]}$, respectively.

Ionophores such as monensin, lasalocid and salinomycin have been shown to exert inotropic effect $^{[8,15-20]}$. This effect has been mostly attributed to the release of endogenous catecholamines ${ }^{[21-23]}$. Vasoactive effect of monensin is also reported to be due to the release of endogenous catecholamine ${ }^{[7]}$. A pronounced increase in plasma catecholamine concentration following salinomycin administration in dogs is reported by Fahim et al..$^{[18]}$. On the other hand, it has been revealed that an in vitro nonpolar interaction occurs between ionophore lasalocid molecule and biogenic amine such as noreadrenaine ${ }^{[9,17,24,25]}$. Therefore, a different postulation could be made to explain the cardiovascular effects of ionophores. This is based on a pharmacokinetic interaction, as ionophores may complex with endogenous catecholamines and hinder their metabolism by various enzymes such as monoamino-oxidase and catechol-O-methyl transferase. The present study was designed to test the above hypothesis. So, the effect of salinomycin on the extent of urinary excretion of one of catecholamine metabolites (VMA) was examined in dogs.

\section{MATERIALS AND METHODS}

Ten healthy female mixed breed dogs weighing 22$29 \mathrm{~kg}$ were randomly divided into two equal groups. Dogs were used in accordance with the international guiding principles involving animals for scientific research at Shiraz University as well as guidelines of the Animal Welfare Act. Two hours before general anesthesia, salinomycin $(22 \%$, donated by Vetak
Pharmaceutical Co., Sirjan, Iran) was orally administered to animals in group II with an equivalent dose of $1 \mathrm{mg} \mathrm{kg}^{-1}$ body weight. Whole egg was used as the vehicle of the ionophore. Adrenaline $\left(10 \mu \mathrm{g} \mathrm{kg}^{-1}\right)$ was intravenously infused to all animals in both groups $30 \mathrm{~min}$ after anesthesia. Normal saline $\left(0.4 \mathrm{~mL} \mathrm{~kg}^{-1} \mathrm{~min}^{-1}\right)$ was administered to each dog via intravenous route with a relatively constant rate during the experiment. The calculated amount of epinephrine was added to the first 0.51 of saline. Urine was collected via urinary catheter at different time intervals (0-30, 30-90, 90-150 and 150-210 $\mathrm{min})$. The volume of urine at each stage was measured and a $50 \mathrm{~mL}$ sample was acidified by adding small amount of hydrochloric acid in order to stabilize the metabolite. VMA contents of urine samples were assayed using Biosystems kits (Costa Brava 30, Barcelona, Spain) by concurrent use of chromatographic separation and spectrophotometric detection according to the modified Wybenga and Pileggi method ${ }^{[26]}$. Detection limit of the method was $1.9 \mathrm{mg} \mathrm{L}^{-1}$ and coefficient of variation was less than 5\%. Data were analyzed by independent Student's t-test.

\section{RESULTS}

Table 1 shows a summary of the data obtained with respect to the effect of salinomycin on the urinary excretion of VMA in dogs. Table 2 shows the total amounts of VMA excreted in urine during various time intervals. Dogs in group I excreted an average of $196 \mu \mathrm{g}$ of VMA in urine compared to $81 \mu \mathrm{g}$ in group II during first half an $\mathrm{h}$ i.e., before intravenous infusion of adrenaline (Table 2).

Table 1: Summary of data obtained from determination of VMA excreted in urines of dogs at various time intervals following intravenous administration of adrenaline $\left(10 \mu \mathrm{g} \mathrm{kg}^{-1}\right)$

\begin{tabular}{|c|c|c|c|c|c|c|c|c|c|c|c|}
\hline \multicolumn{2}{|l|}{ Groups } & \multicolumn{5}{|l|}{$\mathrm{I}^{\mathrm{a}}$} & \multicolumn{5}{|l|}{$\mathrm{II}^{\mathrm{b}}$} \\
\hline \multicolumn{2}{|l|}{ Dog No. $\rightarrow$} & 1 & 2 & 3 & 4 & 5 & 6 & 7 & 8 & 9 & 10 \\
\hline \multicolumn{2}{|l|}{ Body weight $(\mathrm{kg}) \rightarrow$} & 24 & 23 & 26 & 22 & 29 & 23 & 24 & 25 & 28 & 24 \\
\hline \multirow{4}{*}{$\begin{array}{l}\text { Urine volume at } \\
\text { various time intervals } \\
(\mathrm{mL})\end{array}$} & $0-30^{c}$ & 85.0 & 100.0 & 50.0 & 75.0 & 85.0 & 110.0 & 95.0 & 95.0 & 70.0 & 90.0 \\
\hline & $30-90$ & 110.0 & 145.0 & 90.0 & 100.0 & 120.0 & 90.0 & 70.0 & 120.0 & 100.0 & 130.0 \\
\hline & $90-150$ & 45.0 & 90.0 & 140.0 & 140.0 & 90.0 & 120.0 & 105.0 & 80.0 & 95.0 & 65.0 \\
\hline & $150-210$ & 170.0 & 110.0 & 100.0 & 120.0 & 105.0 & 85.0 & 110.0 & 115.0 & 140.0 & 120.0 \\
\hline \multirow{4}{*}{$\begin{array}{l}\text { Urinary VMA } \\
\text { concentration } \\
\left(\mu \mathrm{g} \mathrm{mL}^{-1}\right)\end{array}$} & $0-30$ & 2.71 & 1.69 & 1.69 & 3.49 & 2.75 & 0.56 & 1.18 & 0.75 & 1.07 & 0.94 \\
\hline & $30-90$ & 2.91 & 3.91 & 3.81 & 5.25 & 3.10 & 0.95 & 1.61 & 2.14 & 1.93 & 1.31 \\
\hline & $90-150$ & 3.47 & 4.03 & 4.22 & 8.57 & 3.28 & 1.06 & 2.36 & 1.50 & 2.14 & 1.60 \\
\hline & $150-210$ & 3.75 & 5.61 & 5.92 & 7.09 & 4.65 & 1.13 & 4.51 & 2.68 & 1.72 & 1.88 \\
\hline \multirow{4}{*}{$\begin{array}{l}\text { Total amount of VMA } \\
\text { excreted at various } \\
\text { time intervals }(\mu \mathrm{g})\end{array}$} & $0-30$ & 230.4 & 169.0 & 84.5 & 261.8 & 233.8 & 61.6 & 112.1 & 71.3 & 74.9 & 84.6 \\
\hline & $30-90$ & 320.1 & 567.0 & 342.9 & 525.0 & 372.0 & 85.5 & 112.7 & 256.8 & 193.0 & 170.3 \\
\hline & $90-150$ & 360.0 & 362.7 & 590.8 & 540.0 & 295.2 & 127.2 & 247.8 & 120.0 & 203.3 & 104.0 \\
\hline & $150-210$ & 637.5 & 617.1 & 592.0 & 850.8 & 488.3 & 96.1 & 496.1 & 308.2 & 240.8 & 225.6 \\
\hline
\end{tabular}

${ }^{a}$ : Receiving adrenaline $150 \mathrm{~min}$ after oral whole egg; ${ }^{\mathrm{b}}$ : Receiving adrenaline $150 \mathrm{~min}$ after oral salinomycin $\left(1 \mathrm{mg} \mathrm{kg}^{-1}\right)$ mixed with whole egg; c: Min 
Table 2: Total amounts $(\mu \mathrm{g})$ of VMA in urine samples collected from dogs following intravenous administration of adrenaline $\left(10 \mu \mathrm{g} \mathrm{kg}^{-1}\right)$

\begin{tabular}{|c|c|c|}
\hline Time intervals $(\mathrm{min})$ & Group I $^{\mathrm{a}}$ & GroupII $^{\mathrm{b}}$ \\
\hline $0-30$ & $195.9 \pm 24.7$ & $80.90 \pm 6.2^{\mathrm{S}}$ \\
\hline $30-90$ & $425.6 \pm 43.2$ & $163.7 \pm 23.1^{\mathrm{S}}$ \\
\hline $90-150$ & $429.7 \pm 48.5$ & $160.5 \pm 23.3^{\mathrm{s}}$ \\
\hline $150-210$ & $637.1 \pm 47.8$ & $273.4 \pm 46.1^{\mathrm{S}}$ \\
\hline Mean $\left(\mu \mathrm{g} \mathrm{h}^{-1}\right)$ & $497.5 \pm 30.5$ & $199.1 \pm 23.0^{\mathrm{S}}$ \\
\hline
\end{tabular}

The total amount of VMA excreted in urine during 3090, 90-150 and 150-210 min after administration of adrenaline to dogs in group I were around 426, 430 and $437 \mu \mathrm{g}$, respectively. The corresponding values in group II were found to be 164, 161 and $273 \mu \mathrm{g}$, respectively. In summary, the average rate of VMA excretion were calculated to be around 498 and $199 \mu \mathrm{g} \mathrm{h}^{-1}$ in group I and II, respectively (Table 2).

\section{DISCUSSION}

From previous reports published by other researchers, it seems that the ionophores could alter contraction of the heart simply by releasing catecholamines $^{[17,27,28]}$. Since the release of noreadrenaline from adrenergic nerve endings specifically requires calcium, the action of the antibiotics could involve an alteration in calcium permeability which then leads to a slow, modulated release of transmitter ${ }^{[17]}$. The attenuation of the inotropic effects produced by lasalocid and monensin by beta adrenergic blockers has been the basis of the conclusion that catecholamine release mediates in part the cardiotonic effects of ionophores ${ }^{[15,17,28]}$.

In describing the cardiovascular impact of ionophores, researchers have highlighted the positive effect of these compounds on the release of noreadrenaline. For example, Suchard et al. ${ }^{[22]}$ reported that ionophore monensin stimulates secretion of catecholamine from cultured chromaffin cells via a rise in intracellular sodium. In addition, Perlman et al. ${ }^{[21]}$ have found that a number of carboxylic ionophores stimulate the secretion of noreadrenaline from cell suspensions prepared from a transplantable rat pheochromocytoma. They believed it is likely that ionomycin-induced catecholamine secretion results from the ionophore-mediated entry of $\mathrm{Ca}^{2+}$ into the cells. However, monovalent-cation ionophore monensin was supposed to stimulate catecholamine secretion by a mechanism that is independent of extracellular $\mathrm{Ca}^{2+[21]}$. Moreover, Fahim et al ${ }^{[18]}$ reported that a major part of inotropic effect of salinomycin on the dog heart may be attributed to the release of endogenous catecholamines. No direct analytical confirmation of this in the intact animal has, however, been reported, nor has any relation been established between plasma catecholamine concentrations and the cardiovascular effects produced by ionophores ${ }^{[18]}$. On the other hand, data obtained by Schwartz et al. ${ }^{[16]}$ demonstrates that the ionophore lasalocid (Ro 2-2985) is not a noreadrenaline-releasing agent in a manner similar to tyramine, since even extremely large amounts of the drug do not cause a major demonstrable depletion of noreadrenaline.

It is possible that one of the actions of the ionophore antibiotics is to alter in some way the distribution of certain myocardial factors, one of which could be a histone. It should also be noted that small concentrations of histone produce a highly significant alteration in the inner membrane structure of mitochondria, affecting a passive release of $\operatorname{potassium}^{[16]}$.

Lasalocid can also form lipid-soluble complexes with catecholamines ${ }^{[29]}$ and can transport catecholamines across artificial lipid membranes ${ }^{[30]}$. Triggle $^{[31]}$ has reviewed the subject of ionophoreinduced catecholamine secretion and has proposed that lasalocid may promote catecholamine release from chromaffin cells and sympathetic neurons both by stimulating exocytosis and by acting directly as a catecholamine ionophore.

The study presented here is the first report proposing a different mechanism which is possibly involved in the cardiovascular effects of ionophores. The urinary excretion of VMA during 0-30 min in dogs receiving salinomycin were significantly $(\mathrm{p}<0.05)$ different from that in the control group (Table 2). In addition, dogs in group II (receiving adrenaline after salinomycin) significantly $(\mathrm{p}<0.05)$ excreted less VMA compared to the animals in group I (receiving adrenaline alone).

\section{CONCLUSION}

It is generally concluded that the adrenergic effect of salinomycin may be elicited by a decrease in catecholamine catabolism. Of course, one can make other postulations to describe the involved mechanism of the findings of the present study. For example, salinomycin can compete with VMA to be excreted in urine. Therefore, further works such as measurement of catecholamine concentrations (both parent and metabolites) in serum and determination of other catecholamine metabolites in urine and serum should be 
considered. These may help to more clarify the mechanism(s) involved in this drug interaction.

\section{ACKNOWLEDGEMENT}

We thank Saeed Amirizadeh from Dr. Saadati's Medical Diagnostic Laboratory for his excellent technical assistance in the VMA assay. Generous supply of salinomycin by Vetak Pharmaceutical Company is also greatly appreciated. This study was financially supported by Shiraz University.

\section{REFERENCES}

1. Kinashi, H., H. Otake, H. Yonehara, S. Soto and Y. Saito, 1973. The structure of salinomycin, a new member of the polyether antibiotic. Tetrahedron Lett., 49: 4955-4958. DOI: 10.1016/S00404039(01)87382-2

2. Miyazak, Y., M. Shibuya, H. Sugarvara, C. Kawaguchi, J. Hirose, J. Nagatsu and S. Esumi, 1974. Salinomycin a new polyether antibiotic. J. Antibiot., 27: 814-821.

http://www.ncbi.nlm.nih.gov/pubmed/4452657

3. Dowling, L., 1992. Ionophore toxicity in chickens: A review of pathology and diagnosis. Avian Pathol., 21: 355-368. http://www.ncbi.nlm.nih.gov/pubmed/18670951

4. Callaway, T.R., T.S. Edrington, J.L. Rychlik, K.J. Genovese, T.L. Poole, Y.S. Jung, K.M. Bischoff, R.C. Andeson and D.J. Nisbet, 2003. Ionophores: Their use as ruminant growth promotants and impact on food safety. Curr. Iss. Intest. Microbiol., 4: 43-51.

http://www.ncbi.nlm.nih.gov/pubmed/14503688

5. Moore, C. and B.C. Pressman, 1964. Mechanism of action of valinomycin on mitochondria. Biochem. Biophys. Res. Commun., 15: 562-567. DOI: 10.1016/0006-291X(64)90505-4

6. Pressman, B.C., 1965. Induced active transport of ions in mitochondria. Proc. Natl. Acad. Sci. USA., 53: 1076-1083.

http://www.pubmedcentral.nih.gov/articlerender.fc gi? artid=301375

7. Ozaki, H., T. Kishimoto, H. Karaki, N. Urakawa, 1982. Effects of the $\mathrm{Na}$ ionophore monensin on the contractile response and the movements of monovalent cations in the vascular smooth muscle. Naunyn-Schmiedeberg's Arch. Pharmacol., 321: 140-144. DOI: 10.1007/BF00518482

8. Gupta, R.K., R. Barbbar and M. Fahim, 2005. Effect of ionophore monensin on anaesthetized dogs in hemorrhagic hypotension. Vasc. Pharmacol., 42: 69-75.

http://www.ncbi.nlm.nih.gov/pubmed/15722252
9. Pressman, B.C. and N.T. deGuzman, 1975. Biological applications of ionophores: Theory and practice. Ann. N. Y. Acad. Sci., 264: 373-386. http://www.ncbi.nlm.nih.gov/pubmed/1062961

10. Pressman, B.C. and M. Fahim, 1982. Pharmacology and toxicology of the monovalent carboxylic ionophores. Annu. Rev. Pharmacol. Toxicol., 22: 465-490. http://www.ncbi.nlm.nih.gov/pubmed/7044290

11. Butaye, P., L.A. Devriese and F. Haesebrouck, 2003. Antimicrobial growth promoters used in animal feed: Effects of less well known antibiotics on Gram-positive bacteria. Clin. Microbiol. Rev., 16: $175-188$.

http://www.ncbi.nlm.nih.gov/pubmed/12692092

12. Mitani, M., T. Yamanishi, Y. Miyazaki and N. Otake, 1976. Salinomycin effects on mitochondrial ion translocation and respiration. Antimicrob. Agents Chemother., 9: 655-660.

http://www.pubmedcentral.nih.gov/articlerender.fc gi? artid $=429593$

13. Tsuchida, K. and H. Aihara, 1986. Effects of a K ionophore, lonomycin on the action potential in canine cardiac Purkinje fibers. Jap. J. Pharmacol., 41: 353-361.

http://www.ncbi.nlm.nih.gov/pubmed/3761751?do $\mathrm{pt}=\mathrm{Abstract}$

14. Tsuchida, K. and S. Otoma, 1990. Electrophysiological effects of monensin, a sodium ionophore, on cardiac Purkinje fibers. Eur. J. Pharmacol., 190: 313-320. http://www.ncbi.nlm.nih.gov/pubmed/2272369

15. DeGuzman, N.T. and B.C. Pressman, 1974. The inotropic effects of the calcium ionophore X-537A in the anaesthetized dog. Circulation, 49: 1972-1977. http://circ.ahajournals.org/cgi/content/abstract/49/6/1072

16. Schwartz, A., R.M. Lewis, H.G. Hanley, R.G. Munson, F.D. Dial and M.V. Ray, 1974. Hemodynamic and biochemical effects of a new positive inotropic agent: Antibiotic ionophore Ro 2-2885. Circ. Res., 34: 102-111. http://www.ncbi.nlm.nih.gov/pubmed/4148942

17. Osborne, M.W., J.J. Wenger and M.T. Zanko, 1977. The cardiovascular pharmacology of the antibiotic ionophore Ro 2-2985 (X-537A). J. Pharmacol. Exp. Ther., 200: 195-206. http://jpet.aspetjournals.org/cgi/content/abstract/20 0/1/195

18. Fahim, M., G.D. Valle and B.C. Pressman, 1986. Comparison of the effects of the ionophore salinomycin and adrenaline on the haemodynamics and work efficiency of the dog heart. Cardiovasc. Res., 20: 145-152. http://www.ncbi.nlm.nih.gov/pubmed/3708649 
19. Meral, I., 1998. Effects of different concentrations of monensin on the contractility changes of guineapig papillary muscle. Tr. J. Vet. Anim. Sci., 22: 145-149. http://journals.tubitak.gov.tr/veterinary/issues/vet98-22-2/vet-22-2-6-96107.pdf

20. Satoh, H. and K. Tsuchida, 1999. Pharmacological actions of monovalent ionophores on spontaneously beating rabbit sinoatrial nodal cellsantibiotic ionophore Ro 2-2985. Gen. Pharmacol., 33: 151-159.

DOI: 10.1016/S0306-3623(98)00271-7

21. Perlman, R.L., A.F. Cossi and L.W. Role, 1980. Mechanisms of ionophore-induced catecholamine secretion. J. Pharmacol. Exp. Ther., 213: 241-246. http://www.ncbi.nlm.nih.gov/pubmed/7365686

22. Suchard, S.J., F.A. Lattanzio, R.W. Rubin and B.C. Pressman, 1982. Stimulation of catecholamine secretion from cultured chromaffin cells by an ionophore-mediated rise in intracellular sodium. J. Cell. Biol., 94: 531-539.

http://www.ncbi.nlm.nih.gov/pubmed/7130269

23. Gaide, M.S., J.T. Lehr, S.S. Wong, F.A. Lattanzio and A.L. Bassett, 1984. Comparative study of the effects of salinomycin and monensin on electrophysiologic and contractile properties of canine myocardium. Eur. J. Pharmacol., 100: 321-327. http://www.ncbi.nlm.nih.gov/pubmed/6734723

24. Chalfie, M. and R.L. Perlman, 1976. Studies of a transplantable rat pheochromocytoma: Biochemical characterization and catecholamine secretion. J. Pharmacol. Exp. Ther., 197: 615-622. http://jpet.aspetjournals.org/cgi/content/abstract/19 7/3/615

25. Shen, C. and D.J. Patel, 1977. Biogenic amineionophore interactions: Structure and dynamics of lasalocid (X-537A) complexes with phenethylamines and catecholamines in nonpolar solution. Proc. Natl. Acad. Sci. USA., 74: 4734-4738. http://www.pnas.org/content/74/11/4734.abstract
26. Wybenga, D. and V.J. Pileggi, 1967. Quantitative determination of 3-methoxy-4-hydroxy-mandelic acid (VMA) in urine. Clin. Chim. Acta, 16: 147-154. http://www.ncbi.nlm.nih.gov/pubmed/6036906

27. Sutko, J.L., H.R. Besch, J.C. Bailey, G. Zimmerman and A.M. Watanabe, 1977. Direct effects of the monovalent cation ionophores monensin and nigericin on myocardium. J. Pharmacol. Exp. Ther., 203: 685-700. http://www.ncbi.nlm.nih.gov/pubmed/925964

28. Saini, R.K., R.K. Hester, P. Somani and B.C. Pressman, 1979. Characterization of the coronary vasodilator and hemodynamic actions of monensin, a carboxylic ionophore. J. Cardiovasc. Pharmacol., 1: 123-138.

http://www.ncbi.nlm.nih.gov/pubmed/94374?dopt= Abstract

29. Pressman, B.C., 1973. Properties of ionophores with broad range cation selectivity. Fed. Proc., 32: 1696-1703.

http://www.ncbi.nlm.nih.gov/pubmed/4736349?do $\mathrm{pt}=$ Abstract

30. Kafka, M.S. and R.W. Holz, 1976. Ionophores X537A and A23187. Effects on permeability of lipid biomolecular membranes to dopamine and calcium. Biochim. Biophys. Acta, 426: 31-37. http://www.ncbi.nlm.nih.gov/pubmed/764880?dopt $=$ Abstract

31. Triggle D.J., 1979. Release Induced by Calcium Ionophores. In: Release of Catecholamines from Adrenergic Neurons, Paton, D.M. (Ed.). 1st Edn., Elsevier, USA., ISBN: 13: 978-0080237558, pp: 303-322. 